\title{
Urodimento
}

REVISTA DE ESTUDOS EM ARTES CÊNICAS

E-ISSN 2358.6958

\section{Tra(d)ição como ética decolonial do cabaré sudaca: Cantada em prosa, verso e rebolado!}

Cleber Braga

Para citar este artigo:

BRAGA, Cleber. Tra(d)ição como ética decolonial do cabaré sudaca: Cantada em prosa, verso e rebolado!. Urdimento

- Revista de Estudos em Artes Cênicas, Florianópolis, v. 2,

n. 41, set. 2021.

do) DOI: http:/dx.doi.org/10.5965/1414573102412021e0101

Este artigo passou pelo Plagiarism Detection Software | iThenticate 
Tra(d)ição como ética decolonial do cabaré sudaca:

Cantada em prosa, verso e rebolado!

Cleber Braga ${ }^{1}$

\title{
Resumo
}

Este artigo evoca a tra(d)ição do cabaré, em seu caráter anti-canônico, desde seu surgimento na Europa até a intensificação de sua potência insurgente nos territórios do que se convencionou chamar por América Latina. Assim, operando por contraste, a ruptura com o modelo hegemônico da dramaturgia ocidental, com a divisão entre cultura popular e erudita, com a espacialidade bidimensional, com a branquitude na qual foi engendrado - mas também a sua característica teatromusicalidade, bem como o protagonismo dos corpos femininos e gênero-sexodissidentes -, fornecem subsídios para pensar sobre uma ética decolonial que anima esta maquinaria estética e política, disseminadora de diferenças.

Palavras-chave: Cabaré. América Latina. Decolonialidade. Traição. Teatro.

\section{Tradition/treason as a decolonial ethic of the sudaca cabaret: sung in prose, verse and move!}

\begin{abstract}
This article evokes the tradition/treason of cabaret, in its anti-canonical character, from its emergence in Europe to the intensification of its insurgent power in the territories of what was conventionally called Latin America. Thus, operating by contrast, the break with the hegemonic model of western dramaturgy, with the division between popular and erudite culture, with the two-dimensional spatiality, with the whiteness in which it was engendered - but also its theatricality-musicality, as well as the protagonist of women and gender-sex-dissidents bodies -, provide subsidies for thinking about a decolonial ethics that animates this aesthetic and political machinery, which disseminates differences.
\end{abstract}

Keywords: Cabaret. Latin America. Decoloniality. Betrayal. Theatre.

1 Professor Doutor do curso de Licenciatura em Teatro e do curso de Especialização em Estudos Teatrais Contemporâneos na Universidade Federal do Amapá, do Programa de Pós-Graduação em Ensino e Relações Étnico-Raciais da Universidade Federal do Sul da Bahia. cleberbrag@gmail.com

(3) http://lattes.cnpg.br/8630933424296722 (1) https:///orcid.org/0000-0002-4907-7573 


\section{La tra(d)ición como ética decolonial del cabaret sudaca: ¡Cantada en prosa, verso y danza!}

\section{Resumen}

Este artículo evoca la tra(d)ición del cabaret, en su carácter anti-canónico, desde su aparición en Europa hasta la intensificación de su poder insurgente en los territorios de lo que se ha convencionado llamar de América Latina. Así, operando por contraste, la ruptura con el modelo hegemónico de la dramaturgia occidental, con la división entre cultura popular y erudita, con la espacialidad bidimensional, con la blanquitud en la que se engendró - pero también su carácter teatral y musical, así como el protagonismo de los cuerpos de mujeres y género-sexo-disidentes -, brindan subsidios para pensar una ética decolonial que insufla esta maquinaria estética y política difusora de diferencias.

Palabras-clave: Cabaret. América Latina. Decolonialidad. Traición. Teatro. 
Os recentes estudos sobre a arte do cabaré que se dão no contexto brasileiro vêm contribuindo com a expansão da ideia de "artes cênicas", ampliando ainda mais a diversidade coberta por este termo guarda-chuva. O interesse por este gênero minoritário e engendrado fora do mesmo cânone que orientou a produção de livros sobre a história do teatro ocidental tem corroborado para o transbordamento da ideia de cena e para a inevitável revisão e reconhecimento de espetacularidades insurgentes que tensionam e influenciam as práticas teatrais contemporâneas.

Se em parte é inegável a contribuição de autores como Margot Berthold (2000) para uma historiografia teatral, cujo reconhecimento pode ser constatado pela presença constante de seu nome na bibliografia básica de diversos cursos superiores de teatro brasis adentro, por outro lado essa tendência por adotar perspectivas universalistas caracteriza justamente a pretensa neutralidade do sujeito do discurso eurocentrado, como bem nos alerta a pensadora indiana Gayatry Spivak (2010), denotando uma geopolítica muito específica da produção de conhecimento, cujo modus operandi decalca sobre diferentes realidades o próprio modelo idealizado. Afinal:

Se engana quem pensa que a história é uma faculdade que se atém somente àquilo que deve ser lembrado, a história, como um ofício de tecer narrativas, investe fortemente sobre o esquecimento. Assim, é na perspectiva de produção de não presença da diversidade que se institui uma compreensão universalista sobre as existências. Somos "oficialmente" paridos para o mundo a partir da empreitada colonial (Rufino, 2019, p.14).

Defendo aqui, em sentido contrário, que as ideias de cena e de teatro são capazes de congregar diferentes tipos de teatralidade - esta capacidade humana de ficcionalizar o que se percebe, como defendido por Josette Féral (2003), bem como aquilo que resulta de qualquer tipo de atuação consciente da existência de uma audiência, conforme defendido por Armindo Bião (2009). Tal expansão só é possível desde um descentramento dos parâmetros convencionados pela historiografia hegemônica das artes, decalcada desde o norte global, o que engloba majoritariamente Estados Unidos e Europa. 
Do mesmo modo, novamente por meio desta espécie de expansão diaspórica, as artes da cena, e mais especificamente o teatro, ao desprenderemse de absolutos originários, são capazes de comportar também distintos tipos de espetacularidade - esta "categoria dos jogos sociais onde o aspecto ritual ultrapassa o aspecto rotina" (Bião, 2009, p.163) -, abarcando, assim, manifestações culturais diversas e por vezes negligenciadas pela lógica disciplinar, tão característica da colonialidade.

Neste sentido, pensar sobre uma tradição da arte do cabaré implica no reconhecimento de sua histórica traição ao cânone teatral e, no contexto sudaca², traição ainda à própria colonialidade na qual foi forjado.

\section{(De)colonialidade estética}

Por colonialidade qualifico aqui não apenas o domínio político de determinadas nações sobre suas colônias, mas o legado advindo desta exploração ao longo dos tempos. O racismo que justificou a escravidão de corpos não-brancos por europeus, fossem de negros sequestrados da África ou de povos originários das Américas, tendo por fim a obtenção do lucro, não se findou, por exemplo, com a independência política dos países explorados, permanecendo como uma cicatriz na subjetividade dos atores envolvidos.

Também o machismo que apagou e apaga de forma naturalizada corpos femininos ou feminilizados da vida pública (incluídos aí corpos sexo-gênerodissidentes), divergindo de outras realidades pré-coloniais cujas cosmogonias e ancestralidades concebiam outras possibilidades além do estreito binarismo de gênero imposto por europeus³, é uma evidência de que o cisheteropatriarcado é outro subproduto da colonialidade, segundo a peruana Norma Mogrovejo (2017).

\footnotetext{
2 Sudaca é um termo originalmente ofensivo, utilizado para qualificar migrantes latino-americanos na Espanha, apropriado por esta mesma comunidade minoritária como estratégia identitária para o enfrentamento da xenofobia em território europeu - algo equivalente ao que aconteceu com o termo "queer", nos Estados Unidos, em relação à comunidade LGBTQI migrante.

${ }^{3}$ Um dos múltiplos exemplos disso pode ser encontrado ao sul do México, na figura de pessoas muxe, "termo que se refere a um terceiro gênero dentro da tradição tehuana. Diferente da noção ocidentalizada de transexual ou travesti, ou mesmo de homossexual, ela se insere em um entendimento ancestral sobre o cruzamento da fronteira do gênero e da orientação sexual (Braga, 2019, p.181).
} 
Racismo, machismo e LGBTQIfobia configuram, neste quadro, valores que sustentam este sistema global inaugurado com a expansão colonial-moderna, mais especificamente desde a invenção da América, e que:

Tem em comum três elementos centrais que afetam a vida cotidiana da totalidade da população mundial: a colonialidade do poder, o capitalismo e o eurocentrismo. Claro que este padrão de poder, nem nenhum outro, pode implicar que a heterogeneidade histórico-estrutural tenha sido erradicada dentro de seus domínios. O que sua globalidade implica é um piso básico de práticas sociais comuns para todo o mundo, e uma esfera intersubjetiva que existe e atua como esfera central de orientação valorativa do conjunto. Por isso as instituições hegemônicas de cada âmbito de existência social, são universais para a população do mundo como modelos intersubjetivos. Assim, o Estado-nação, a família burguesa, a empresa, a racionalidade eurocêntrica (Quijano, 2005, p.123124).

Este piso básico de práticas sociais do qual nos fala o também peruano Aníbal Quijano (2005) resulta em uma ferida aberta, uma ferida colonial que expõe a desvalorização de tudo o que se distancie do cânone euroestadunidense. É neste sentido que, reconhecidas apenas por seu autoctonismo, manifestações culturais e artísticas não-canônicas serão historicamente desvalorizadas em relação ao imaginário imposto por este mesmo universalismo. Racializadas e folclorizadas, manifestações dissidentes serão tomadas por artesanato, arte menor, baixa cultura, gerando um inevitável sentimento de defasagem em relação ao cânone, como nos fala a argentina Zulma Palermo (2009), e fazendo com que boa parte da energia vital de artistas periféricos seja empregada na mimese do colonizador.

Contudo, defendo aqui a possibilidade de uma reformulação desta estéticosubjetividade colonial, no sentido da (re)valorização de elementos recalcados. Tal reformulação, em perspectiva ética, é baseada em uma atitude crítica, incompleta e por isso mesmo contínua, que constata e questiona o modelo imposto para então empreender sua energia vital na reconfiguração dos padrões herdados, conformando uma consciência decolonial que :

Busca decolonizar, des-segregar e des-generar o poder, o ser e o saber (Maldonado-Torres, 2007a). Isto é feito ao criar laços e novas formas entre esferas que a Modernidade ajudou a separar: a esfera da política ou do ativismo social, a esfera da criação artística e a esfera da produção de conhecimento. A consciência decolonial acarreta formas de atuar, de ser 
e de conhecer que se alimentam dos encontros entre estas áreas. Neste sentido a consciência decolonial é uma consciência limítrofe e seu pensamento também é um pensamento de fronteira que se nutrem da experiência de estarem marcados pela linha ontológica moderno-colonial (Anzaldúa, 2012). O caráter fronteiriço do pensamento decolonial também aponta para seu caráter transdisciplinar: o projeto e a atitude decolonizadora leva o sujeito cognoscente que emerge da zona do não ser a alimentar-se do ativismo social, da criação artística e do conhecimento (em algum caso também da espiritualidade) em vias de revelar, desmantelar e superar a linha ontológica moderno-colonial (Maldonado-Torres, 2016, p.94).

Nessa perspectiva, os estudos de cabaré, no contexto brasileiro e sudaca, forjam novos possíveis na cena contemporânea, dada sua natureza fronteiriça. Congregando estética e política, eles dizem respeito a um conjunto de práticas transdisciplinares e movediças que transgridem o padrão classificatório, disciplinar. Um exemplo disso é a conexão que promovem entre cena e música sem, contudo, recaírem na tradição espetacular da ópera, tampouco do teatro dramático.

Contudo, transbordando o modelo de hibridismo que preserva absolutos originários de linguagens artísticas justapostas -, a exemplo de noções como a de teatro-música ou de teatro-dança -, nos cabarés brasileiro e sudaca a soma das partes resulta em algo maior e diverso, como na consciência mestiza idealizada pela chicana Gloria Anzaldúa (2015, p.140), cuja “energía proviene del contínuo movimiento creativo que persiste em disolver el aspecto unitario de cada nuevo paradigma”. Deste modo, projeta-se do cabaré sudaca, forjado nas ex-colônias, uma maquinaria contracolonial disseminadora de diferenças, que em parte mantém-se fiel à tradição popular e anti-burguesa do gênero, no que diz respeito a sua pré-história europeia e, por outro lado, trai a própria colonialidade do poder no qual foi forjado e imposto: pura tra(d)ição.

\section{1a tra(d)ição: Não, no princípio não era o verbo}

O cabaré é um exemplo de transbordamento ao inaugurar modos espetaculares que se dão em perspectiva cênica sem, contudo, estarem restritos 
a uma linguagem artística específica, nem terem se desenvolvido, por exemplo, sobre o pano de fundo da tradição dramatúrgica ocidental. Vale notar que autores como Peter Szondi (2001) já apontaram para a existência, na dramaturgia europeia do final do século XIX, de alternativas ao modelo de representação aristotélica pautado pela verossimilhança e pela estrutura sólida da narrativa mítica, com começo, meio e fim bem definidos, conforme defendido por Aristóteles (2007).

Autores como Jean Pierre Ryngaert (1998) também demonstram como a dramaturgia incorporou, ao longo do século XX, uma capacidade de abertura ou mesmo incompletude que convoca a subjetividade do espectador a atuar como um importante catalizador da experiência teatral. Assinalo, com tais exemplos, que há muito a ideia de dramaturgia não pode ser tomada como um monólito, uma superfície homogênea, pois está em constante reelaboração.

Entretanto, a tradição do cabaré implica nesta primeira grande traição: ela desconstrói, em sua gênese difusa, a autoria única. O cabaré rompe com a compreensão de teatro enquanto desdobramento de uma literatura, rompe com o jogo segundo o qual cabe aos atores, diretores e demais sujeitos do espetáculo a ilustração do que foi escrito previamente pelo autor - compreensão predominante no ocidente e balizadora do gênero dramático, conforme posto por Hans This Lehmann (2007).

Diferente disso, por meio do choque entre os corpos do público, do lugar, dos distintos atuantes - malabaristas, dançarinos, músicos, etc. -, é que foi projetada esta espetacularidade de acontecimento - isto que para Michel Foucault não se restringe, contudo, à fisicalidade dos corpos, já que:

A física diz respeito às causas; porém, os acontecimentos, que não são os seus efeitos, já lhe não pertencem. Imaginemos uma causalidade enterrada; os corpos ao chocar, ao misturarem-se, ao sofrer, causam na sua superfície acontecimentos que não tem espessura nem mistura, nem paixão, e não podem ser portanto causas: formam entre si outra trama na qual as uniões manifestam uma quase-física dos incorporais, assinalam uma metafísica (Foucault, 1995, p.40).

Liberto do ciclo de causalidades do tempo, o acontecimento se desprende da órbita do "eu" que o interpreta - como um baile de máscaras sem ninguém que 
as manipule. Improgramável, imprevisível, incontrolável: como seria possível pensá-lo em termos de autoria?

Teatralidade projetada do acontecimento ébrio, o cabaré não provém de uma materialidade textual como outras modalidades teatrais europeias, assombrando toda uma tradição dramatúrgica. Desde sua origem intáctil, ele dilui o racionalismo eurocêntrico que para Quijano (2005) é basilar da colonialidade ainda em curso. Difuso como vapor alcóolico, o cabaré reverbera nas ondas sonoras, vibra na rede de corpos de onde emerge o espetáculo-acontecimento.

\section{2a tra(d)ição: Impuro pela própria natureza}

Neste ponto, o paralelo com a arte da performance é inevitável. Se considerarmos que a performance enquanto arte está ligada às vanguardas europeias do começo do século XX; que dá ênfase ao corpo em detrimento à qualquer dramaturgia escrita previamente, numa perspectiva crítica ao logocentrismo discursivo; que se desenvolve enquanto arte de fronteira, situandose entre distintas linguagens artísticas, das quais se vale, sem estar presa a nenhuma especificamente; e que estabelece uma relação presencial entre atuante, público e texto - ainda que, por vezes, não verbal, o que permite interpretá-la também como arte de cena, na acepção de Renato Cohen (2009) -, podemos ter em mente a relação intima com a ideia de cabaré.

Tal intimidade se acentua se considerada a mesma origem controversa. Afinal, o termo cabaret surge na França por volta do século XV para denominar tavernas onde apresentações variadas entretinham o púbico, estimulando o consumo de álcool. Nos séculos subsequentes, estas apresentações, com forte teor de improviso e sempre em relação direta com o público, forjaram o cabaré enquanto um gênero teatral, como afirma Lívia Sudare (2019).

De forte musicalidade, consequência da influência sofrida pela chanson, gênero musical francês desenvolvido no mesmo período, a prática do cabaré se populariza nestes espaços noturnos ao longo da Europa não apenas entretendo mas também debatendo questões da vida política. Segundo Roselee Goldberg 
(2006), este modelo espetacular popular e de espacialidade nada ortodoxa servirá de inspiração para os movimentos de vanguarda - interessados que estavam por mesclar arte e vida, bem como por romper com a moralidade burguesa vigente e que, por sua vez, inaugurarão as práticas de performance arte.

Assim, na passagem do século XIX para o século XX, a arte da performance se cruza com a prática do cabaré no contexto utópico das vanguardas artísticas europeias, no controverso ambiente de uma modernidade que, segundo Santaella (2009), estava disposta a inaugurar um mundo diverso, uma nova humanidade marcada pelo poder da arte, desprendida dos velhos valores que levaram, entre outros problemas, às guerras mundiais.

É a partir deste ponto que outra importante tra(d)ição se desenha. Após trair o cânone teatral de base dramatúrgica, o cabaré afirma-se enquanto espetacularidade popular e erudita, ao mesmo tempo, desfazendo as dicotomias entre alta e baixa cultura, tradição e vanguarda:

Por causa de sua abrangência extremamente eclética e provavelmente porque procurou desde o início utilizar formas populares de novas maneiras, o cabaré teve uma carreira mais longa e atraiu um público maior e mais diversificado do que as muitas vanguardas artísticas mais especializadas e esotéricas que, em parte, emergiram dele. Tanto no ecletismo quanto no apelo de seus criadores boêmios a um público mais geral, o cabaré prefigura mais a dinâmica da performance moderna do que a dinâmica de qualquer dos movimentos de vanguarda especializados (Carlson, 2009, p.101).

O cabaré é múltiplo, gênero teatral de forte performatividade, segundo a qual a obra "não existe senão por sua lógica interna que the dá sentido, liberando-a, com frequência, de toda dependência, exterior a uma mimeses precisa, a uma ficção narrativa construída de maneira linear" (Féral, 2008, p.209). Ao mesmo tempo, mantém sua capacidade de comunicação direta com um público mais amplo e diverso, o que não pode ser dito de outras modalidades artísticas também herdeiras das vanguardas europeias, de alcance restrito a públicos mais específicos e especializados.

\section{3a tra(d)ição: Teatralidade sem teatro}

Arquitetura é poder. Qualquer proposição arquitetônica transparece o 
desejo, o modo como seu autor idealiza que se deem as relações em uma espacialidade específica. Semelhante a um fóssil, o edifício opera como vestígio de determinada sociedade, ao longo do tempo, denotando características de sua cultura. No caso do teatro, palavra que qualifica tanto o fazer artístico quanto o lugar onde isso é feito, a relação entre espaço e acontecimento é evidente.

Tomando por exemplo o modelo do palco italiano, predominante ainda hoje, a estrutura arquitetônica faz com que a própria ideia de teatro seja comumente interpretada como sinônimo deste tipo de espacialidade. Assim, a delimitação da área da cena, em perspectiva bidimensional, ocupada apenas pelo artista - o que dificulta a interação com o público, mergulhado no escuro da sala fechada, em silêncio -, são algumas das particularidades que se estabeleceram como norma.

É interessante notar que tal espacialidade, forjada no contexto do Renascimento europeu, aponta para o que Roubine (1982) identifica como consequência de uma hierarquia social emergente, segundo a qual teriam direito aos lugares mais privilegiados entre o público aqueles que possuíssem mais posses e prestígio social. Contudo, antes e depois de aristocratas e burgueses contribuírem para a normatização do palco italiano, outras proposições espaciais sempre configuraram teatralidades alternativas a este cânone, estabelecendo relações mais diretas com o tecido urbano, com espaços públicos, mercados e feiras, ou até mesmo tomando a cidade toda e envolvendo multidões (Cruciani; Falletti, 1999).

No que diz respeito ao cabaré, sua teatralidade historicamente corresponde a um espaço cênico difuso, onde artista e público estão em contato direto, afetando-se mutuamente. O contexto boêmio, o álcool e a música contribuem para um relaxamento das fronteiras que objetivam manter o público no seu devido lugar. Diferente disso, o cabaré é, por tra(d)ição, um lugar de experiência compartilhada, de encontro mais horizontalizado:

O intuito primário do Cabaré foi a criação de um espaço para o desenvolvimento, debate e apresentação de chansons. Essa ideia de espaço criativo expandiu-se, trazendo para o debate outros tipos de inventividades artísticas e nasceu assim, em 11 de outubro de 1878, o primeiro cabaré literário de Paris, chamado de Les Hydropathes. 
Os membros da sociedade literária Hydropathes encontravam-se uma vez por semana para que escritores, poetas e artistas pudessem compartilhar seus trabalhos, que podiam ser poesias, canções, monólogos e pequenas esquetes.

[...] Em 1881 foi fundado o cabaré Chat Noir que consolidou a ideia do cabaré enquanto um espaço social; enquanto um espaço para a discussão política e para a transgressão de regras (Sudare, 2019, p.50).

Assim, historicamente, a espacialidade do cabaré permitiu o desenvolvimento de uma teatralidade que não oculta nem silencia seu público, ao contrário, convida-o à transgressão das convenções sociais, algo impensável de acontecer no tipo de edificação predominante dos teatros, que ratificam as hierarquias sociais vigentes.

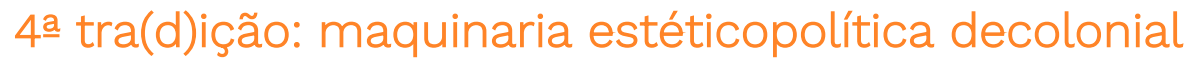

Práticas espetaculares desembarcam em terras brasileiras como parte de um ideal de civilização imposto, uma mimese das metrópoles. Afinal, que outra coisa traduziria melhor o projeto da colonial-modernidade senão o desejo narcísico do colonizador de ver-se replicado mundo à fora como um modelo a ser seguido? Neste ponto, é importante não perder de vista que a linguagem teatral chega ao território brasileiro pelas mãos dos padres jesuítas, conscientes que eram da eficiência da cena enquanto ferramenta pedagógica para a catequização e consequente imposição da língua portuguesa.

Para Lúcia Lobato (2011), neste contexto, o teatro serviu também para implementar o mito do homem sério, que diz respeito ao sujeito temente ao Deus cristão, de moral recatada e cujo corpo, desde processos de racialização, passa a dedicar-se tão somente ao trabalho que, em última instância, é capitalizado pelo colonizador. Por consequência, dimensões lúdicas preponderantes em corporalidades não brancas foram recalcadas pelo processo de subjetivação colonial. E, acrescento eu, é inaugurada a performance segundo a qual a sociedade deste país recém inventado se divide entre os que são espoliados e os que se apropriam - herança maldita que reencenamos desde então.

Contudo, como nenhuma dominação pode ser absoluta, os sotaques e jeitos locais macularam o cânone, burlaram as regras, deram o tom da (re)existência nas diversas teatralidades populares: 
Que podem ser separadas em compartimentos, em seções, sem que haja interferência de informação de um para o outro. São os espetáculos de variedades nos quais um esquete pode ser seguido de um número de dança, que por sua vez poderá ser seguido por um quadro de malabaristas ou por uma declamação sentimental, etc. Seguem tal modelo o circo, a pantomima, o music-hall, o cabaré, a ópera bufa, o Teatro de Revista (Veneziano, 2013, p.24).

Assim, gêneros irmanados desde o modelo não-dramático de espetáculo de variedades, a exemplo do teatro de revista - que para Christina Streva (2019) guarda íntimas semelhanças com o cabaré no contexto carioca do início do século XX, ainda que ambos não possam ser tomados como sinônimos -, lograram popularidade local e, indo além, singularizaram os códigos herdados, abrasileirando espetacularidades hegemônicas. Neste processo de singularização, aquilo que já era marginalizado, tido por arte menor, menos séria na Europa, mas que se estabeleceu predominante nas colônias por meio de um processo contínuo de imposição de teatralidades eurocentradas, potencializa a própria diferença ao distanciar-se do cânone ainda mais, para além do que já havia se distanciado.

Defendo a ideia de que, de modo geral, o cabaré tem radicalizado sua tra(d)ição transgressora nas ex-colônias porque seu espírito provocador e político, que historicamente se rebelou à moralidade vigente, aos cânones estéticos, encontra terreno fértil nos territórios violentados pela exploração colonial, pela desigualdade social baseada na racialização dos corpos, na misoginia e na LGBTQIfobia, entre outras heranças da invenção da América.

A este respeito contribui muito a percepção de Christina Streva (2019) sobre o florescimento do cabaré carioca, a partir da década de 1920, enquanto uma prática estético-política transgressora da moralidade da época e de sua naturalização da hierarquia social, a exemplo do que aconteceu na Europa. Contudo, segundo a autora, deste lado do Atlântico o cabaré visibilizou também a existência de artistas negros e marginalizados até então - tensionando a branquitude caracacterística do gênero, se considerada a lógica de importação de artistas, espetáculos e modelos estrangeiros.

Por branquitude não qualifico apenas a condição de sujeito cuja pele apresenta menos melanina, senão toda uma estrutura social baseada no jogo 
narcísico segundo o qual determinados espaços de poder são reservados para sujeitos brancos por outros sujeitos brancos sem que se isso seja questionado. Para Lia Vainer Schucman (2014, p.84), a minoria de estudos sobre o tema coerente com a maioria branca que tem acesso às Universidades latinoamericanas - corrobora com a naturalização do racismo, afinal:

\begin{abstract}
A branquitude é entendida como uma posição em que sujeitos que ocupam esta posição foram sistematicamente privilegiados no que diz respeito ao acesso a recursos materiais e simbólicos, gerados inicialmente pelo colonialismo e pelo imperialismo, e que se mantêm e são preservados na contemporaneidade. Portanto, para se entender a branquitude é importante entender de que forma se constroem as estruturas de poder fundamentais, concretas e subjetivas em que as desigualdades raciais se ancoram.
\end{abstract}

Isso leva a pensar que se por aqui o cabaré radicaliza no âmbito de sua tra(d)ição, é porque literalmente mudam seus atores, são outros os corpos a se apropriarem, gradativamente, da cena e de seus modos de produção. Os cabarés brasileiro e sudaca, dada sua relação com o próprio processo de imposição de teatralidades europeias, que recalcaram teatralidades múltiplas existentes na Abya Yala ${ }^{4}$ - é incapaz de negar sua origem colonial, nem tampouco a branquitude no qual foi engendrado. Ao mesmo tempo, tendo se desdobrado em outras corporeidades e geopolíticas, pôde se reconfigurar como maquinaria estéticopolítica decolonial, desconstruindo e reformulando padrões estéticos vigentes.

Um exemplo do que digo é o espetáculo Cabaré da Rrrrraça, encenado pelo Bando de Teatro Olodum, na cidade de Salvador, em 1997. Valendo-se dos elementos característicos da teatralidade do cabaré, o espetáculo configurou-se como um marco da afirmatividade negra na Bahia. Composto por artistas negros, Cabaré da Rrrrraça tematizou o racismo cotidiano e seu enfrentamento por meio das cenas, das coreografias e das diversas músicas que reconectavam ativismo político e arte no espaço do Teatro Vila Velha - cuja ocupação, heterodoxa, se dava

${ }^{4}$ Abya Yala é um termo usado pelo povo Kuna, do Panamá, para qualificar o território conhecido por América, mas cujo uso se popularizou no sentido de uma autodesignação de outros povos originários (PortoGonçalves, 2009). 
em perspectiva tridimensional (Itaú Cultural, 2017).

Devo dizer que me tornei especialmente sensível a esta possibilidade de reconexão, no contexto das práticas de cabaré, depois de realizar a direção artística e dramaturgia do projeto Cabaret Glicose: um cabaret decolonialista? janeiro de 2015 dentro do Festival O Bairro i o Mundo, na cidade de Loures localizada no Distrito de Lisboa, em Portugal. Cabaret Glicose é um espetáculo do repertório do Elenco de Ouro, grupo com o qual trabalhei ao longo de 15 anos na cidade de Curitiba, tendo estreado em 2007. Nesta versão portuguesa, contou com a parceria do coletivo Casa Selvática ${ }^{6}$, também de Curitiba, e do português Teatro Ibisco ${ }^{7}$ (Teatro Inter Bairros para a Inclusão Social e Cultura do Optimismo), que realiza ações culturais nos bairros Quinta da Fonte e Quinta do Mocho, duas regiões discriminadas pela alta concentração de migrantes oriundos de países africanos lusófonos e/ou falantes de crioulo de base portuguesa.

Este projeto, em sua versão portuguesa, realizou também uma série de oficinas com moradores da região e com atores do Teatro Ibisco, o que permitiu uma aproximação ainda maior entre todos. Talvez por tratar-se de uma crítica ao processo colonial no qual foram engendrados países como Brasil, Cabo Verde, São Tomé e Príncipe, Guiné-Bissau, entre outros, o projeto denotou uma forte conexão entre o elenco brasileiro e os migrantes africanos, não deixando de apresentar momentos de tensão, como o que descrevi em minha tese de doutorado, no qual:

um dos atores, Stéfano Belo, recitou uma versão do poema musicado Me gritaron negra, da artista peruana Victoria Santa Cruz (2018). Quando de sua estreia em Portugal, havia uma certa insegurança na realização deste número. O poema relata a primeira vez em que a autora percebe-se negra e descreve o processo de transição do sentimento de vergonha ao sentimento de orgulho de sua negritude. Ocorre que o ator baiano não era considerado negro em sua terra de origem, tampouco identifica-se ou era identificado como mulher - ainda que algo de indefinido em sua corporeidade servisse como deslocamento, provocação, e dificultasse sua identificação enquanto sujeito branco e masculino, nas suas acepções mais hegemônicas. Além disso, a declamação do poema

${ }^{5}$ Este projeto foi realizado por meio do Edital Conexão Cultural Brasil intercâmbios, do Ministério da Cultura do Brasil.

${ }^{6}$ Maiores informações sobre a Casa Selvática em: https://www.selvatica.art.br/ Acesso em 15 mar. 2021.

Maiores informações em: http://www.ibisco.org/ . Acesso em: 15 mar. 2021. 
desdobrava em outra cena na qual Stéfano amamentava a figura de um português moribundo, compondo uma espécie de Pietá, de Michelangelo, que representa Jesus morto nos braços da Virgem Maria. O risco de ser "mal interpretado" era grande.

O início da cena causou tensão. Muito diferente da polidez desinteressada de algumas plateias habituadas a ir ao teatro, o público em Loures era vivíssimo e reagia. Gargalhou diante da imagem do homem vestido de mulher, numa ridicularização. Mas, à medida em que o texto transcorria e o jogo de cena se estabelecia, passou das gargalhadas ao silêncio, que só foi quebrado quando alguém gritou: "É o nosso povo!". Esta afirmação desencadeou uma série de manifestações. O pequeno teatro superlotado acabou por aplaudir a cena de pé, para nosso espanto. Parte do público ficou visivelmente comovida. Parte de nós também (Braga, 2019, p. 64).

A partir daquele momento, a atriz Stéfano Belo passou a se compreender como pessoa não-binária, transfeminina, travesti, em suas próprias palavras, segundo comunicação informal estabelecida comigo - razão pela qual atualizo aqui as terminologias adotadas neste trecho da Tese. A potência de sua performance fronteiriça, contudo, efetiva-se ao longo do tempo. A crítica do jornalista português Luís Guita (2015, s/p), publicada dias depois, foi importante no sentido de mensurar o impacto da experiência não apenas para o público migrante:

Se há quem tenha dúvidas a respeito da força transformadora que uma peça de teatro pode exercer sobre o público, se há quem se interrogue acerca do poder de um bom ator face a um público céptico, bastaria assistir a Cabaret Glicose e ver como uma sala cheia se pode unir no reconhecimento de uma identidade e manifestar a sua humanidade.

Longe de elitismos artísticos e de qualquer tipo de paternalismos, foi com a sua frontalidade que o Elenco de Ouro conquistou os portugueses e os agitou na direção de um questionar da existência.

O grande Portugal, senhor colonial, que agora é vassalo da Europa. O negro que tem prazer na sua cor e cultura. As fronteiras que foram desenhadas num mapa, mas sem sentido no dia a dia de homens e mulheres. São temas que tocam na carne de muitos portugueses, em particular aqueles com origens em países africanos de língua portuguesa, e por isso, mesmo durante a apresentação, o público não se escondeu e manifestou, bem alto, o prazer em se reconhecer naquele Cabaret Glicose.

"São coisas que fazem parte da cultura do Brasil mas também da nossa cultura. Nós não somos de um só país. Somos de Portugal, do Brasil e de outros países também", comentou Bruno da Costa, da Guiné-Bissau, há 11 anos em Portugal, à saída do espectáculo. E, com uma pontinha de ironia, acrescentou: "Tal como Portugal foi um grande país e agora tem de limpar banheiros, aqueles que hoje são grandes senhores não pensem que o serão para todo o sempre" (Guita, 2015, s/p.) 
O modo como a equipe do Teatro Ibisco, bem como seu público, composto basicamente por pessoas negras e africanas, reagiu ao espetáculo de artistas brasileiros sobre heranças compartilhadas no âmbito da colonialidade, disse-me muito sobre a efetividade da arte na abordagem das feridas coloniais e, mais especificamente, da arte do cabaré - quando fiel às suas tra(d)ições. Pude compreender ali, em sintonia com Walter (Mignolo, 2016), que "para la sanación decolonial no se necesitan psicoanalistas".

\section{5a traição: Teatromusicalidade}

Outro exemplo significativo deste processo de abrasileiramento ou singularização do cabaré e de outros gêneros espetaculares de variedades é a relação entre dramaturgia e música popular. No caso do Teatro de Revista, por exemplo, afirma Neide Veneziano (2013, p.68) que:

Após a explosão da Primeira Grande Guerra, a música, que até então tinha sido incidental e reduzida a meras ilustrações, adquiriu o mesmo peso do texto. Um grande apuro e cuidado fizeram-se sentir nas composições musicais. Chegou-se a uma nova fórmula, tipicamente brasileira, afastada do modelo luso-francês. A melodia, agora, era parte integrante do conjunto.

A relação entre melodia e texto literário tem sido objeto de interesse de diversos artistas e pesquisadores. José Miguel Wisnik (2019), por exemplo, reconhece no cancioneiro nacional a presença do que qualifica como alta poesia. Atribui esta íntima relação entre texto e som à melodização particular do português brasileiro, que potencializa a palavra, levando-a além do que seria enquanto literatura.

Neste sentido, a tradição musical do cabaré, presente desde a chanson française, passando pela interpretação da música narrativa idealizada por Bertold Brecht (1967) em seus espetáculos, parece ter ganho outros tons em território brasileiro, a ponto de aquilo convencionado por trilha sonora se reconfigurar no que, habitualmente, é entendido como dramaturgia de um espetáculo teatral.

Reconheço como possível desdobramento do que descrevo o método de 
treinamento de atores denominado gira, idealizado por Amir Haddad. Nele, improvisações coletivas são propostas desde estímulos sonoros conjugados à estímulos visuais: figurinos, adereços, ou apenas tecidos dispostos em determinada espacialidade. À medida em que as músicas são executadas, os atores - valendo-se do imaginário dos espetáculos de cabaré, de teatro de revista, entre outras espetacularidades populares de variedades -, se lançam em improvisações situadas na fronteira entre o teatro, a dança, o circo, etc., tendo por subsídio dramatúrgico, sobretudo, a música.

Mesmo quando não possuem texto cantado, as melodias utilizadas servem de base para a confecção de elaboradas cenas coletivas, sendo este um método aplicado também para composição de espetáculos ${ }^{8}$. Vale notar que a expressão gira qualifica também a manifestação de espíritos ou orixás no contexto da umbanda e candomblé, religiões de matriz litúrgica africana e pautadas pela incorporação das divindades pelos fiéis, em sintonia com seus respectivos estímulos sonoros.

Em sentindo contrário, é possível constatar a existência de cantores que evocam a teatromusicalidade, numa possível conexão com mesma tra(d)ição de cabaré brasileiro. São exemplos disso a cantriz Cida Moreira, que ao longo da carreira vem interpretando versões de standards da parceria entre Bertold Brecht e Kurt Wild, bem como de Chico Buarque e Ruy Guerra, em shows de forte teatralidade - a exemplo de sua versão do clássico Surabaya Johnny (Brecht; Weill, 1983).

Também a modalidade de espetáculo musical desenvolvida por Fauzy Arap juntamente com a cantora Maria Bethânia, que intercala textos poéticos e canções em números variados, remete à figura de cabaretier em sua performance de fronteira - a exemplo dos espetáculos Drama 3ํ Ato: Luz da Noite (Bethânia, 1973) e A cena Muda (Bethânia, 1974), ambos registrados ao vivo em disco.

${ }^{8}$ Nos dois anos em que fui estudante da Escola Carioca do Espetáculo Brasileiro e atuei como ator junto ao Grupo Tá Na Rua, ambos sobre direção de Amir Haddad, no Rio de Janeiro, esta metodologia foi especialmente marcante para mim. Devo dizer que valho-me ainda hoje de tal referência em minhas práticas cênicas. 


\section{6a tra(d)ição: desobediências feministas}

Me dicen mala hierba porque nunca me dejé morir Siempre viva como mala hierba! (Rebeca Lane, 2018)

Não seria exagero afirmar que a objetificação do corpo feminino é recorrente no imaginário dos espetáculos de variedades. Pernas ao ar abundam ainda hoje em espetáculos não necessariamente críticos ao sistema patriarcal, a exemplo do Moulin Rouge ${ }^{9}$, de Paris. Ali, a tradição não arranha o machismo, nem a branquitude reencenada tanto no palco quanto na presença de um público composto, em grande parte, por turistas abastados - o que denota também a manutenção da hierarquia social.

Essa obediência ao status quo corresponde a um processo de espetacularização, segundo a acepção de Guy Debord (1972, p.8), para quem: “Toda a vida das sociedades nas quais reinam as modernas condições de produção se apresenta como uma imensa acumulação de espetáculos. Tudo o que era vivido diretamente tornou-se uma representação". Nesse sentido, o Moulin Rouge de Paris faz a representação de uma tradição sem qualquer traição.

Apesar disso, a exposição por vontade própria, no ambiente público do cabaré, pode configurar também uma desobediência, um fortalecimento feminino no sentido da autonomia sobre o próprio corpo. Seguindo tal perspectiva, outra relevante tra(d)ição do cabaré foi a ocupação da cena por mulheres, historicamente restritas ao lar, no contexto das urbanidades modernas. Afinal:

Uma das dicotomias que organizaram o pensamento moderno consistiu na separação entre as esferas pública e privada, que se constituiu como efeito da ascensão da burguesia, no modo capitalista de produção. Nesta dicotomização, as mulheres foram destinadas às funções nos espaços privados, enquanto os homens tiveram acesso aos espaços públicos de trabalho. As funções valorizadas eram as exercidas nos espaços públicos, de decisões políticas, enquanto os trabalhos realizados nos espaços domésticos, privados, foram sempre considerados de menor valor (Lago, Souza et al, 2009, p.358).

9 Maiores informações sobre o Moulin Rouge estão disponíveis em: < http://www.moulinrouge.fr/feerieshow?lang=en\#>. Acesso em: 05 abr. 2021. 
Ainda que na Abya Yala relações generificadas existissem antes mesmo da colonialização europeia, denotando alguma hierarquia, estas configuravam tão somente um patriarcado de baixo impacto, conforme defendido pela argentina Rita Segato (2012). Isso porque as mulheres ocupavam o espaço público, manifestando-se politicamente dentro de sua comunidade, algo que só foi interrompido com a figura do homem branco e seu modelo mais restritivo de generificação do espaço público. Ao explorar e humilhar publicamente o homem colonizado, o colonizador inaugura também uma modalidade impensável de violência. Por resultado, a dor, a humilhação e o ódio do homem colonizado recaíram sobre corpos femininos, a esta altura já restritos ao lar e compondo com os filhos parte da propriedade privado do marido - numa espécie de simulacro do patriarcado europeu, só que agora mais violento.

Protagonistas na apresentação de seus números, mulheres cabareteiras gozam de reconhecimento público e estimulam outras mulheres a viverem sua autonomia, numa quebra do paradigma moderno-colonial. Este é o caso do burlesco, gênero muito presente em cabarés, de humor provocativo, forjado no contexto dos espetáculos de variedades e que, a partir do século XIX, se caracteriza pela atuação de mulheres que expõe o corpo em desobediência às normas morais vigentes. Ainda que oriundo da Europa:

Podemos já perceber que, ao menos no Novo Mundo, a questão de gênero é indissociável da cena burlesca, em toda sua ambiguidade política. Se, por um lado, a presença feminina é explorada como um chamariz de público, por outro viés, a mulher muitas vezes tomou o espaço da cena para exercer sua voz política, construindo um campo de possibilidades através do exercício da atuação. A sensualidade e o erotismo são usados tanto por produtores espertos quanto por atrizes perspicazes que encontram no exercício de produção de erótica um lugar de afirmação de diferença (Saidel, 2011, p. 46-47).

Ao mesmo tempo em que a exposição de corpos femininos pôde ser capitalizada pelo sistema patriarcal, ela abriu espaço para a quebra de paradigmas sexistas, potencializando movimentos emancipatórios e interseccionais. O corpo da mulher gorda, por exemplo, rechaçado pelo machismo gordofóbico, é exaltado por representantes do New Burlesque, movimento que conecta o gênero com 
questões da atualidade. No Brasil, o trabalho das artistas Delirious Fênix e Mister G são dois exemplos desta conexão entre a arte do burlesco e o confronto aos padrões estéticos impostos aos corpos femininos.

Nesta fronteira entre ativismo feminista e arte atua também a colombiana e residente no México Nadia Granados. Muito marcada por seu ativismo social, tendo colaborado com o movimento intitulado Congreso de Los Pueblos ${ }^{10}$, entre outros, Nadia chega à arte do cabaré pelo desejo de congregar erotismo e política, como declarou em uma entrevista que me concedeu na cidade de Salvador, em 2018, por conta de sua participação em um festival (Braga, 2019).

Valendo-se do estereótipo de femme fatale, que recai sobre mulheres latinas, a artista forjou a persona de La Fulminante, espécie de monstro hiperfeminilizado que assombra o patriarcado narco e necropolítico por meio de suas performances que se aproximam das práticas pós-pornográficas. A póspornografia constitui um movimento de reação ao feminismo abolicionista que se posicionou historicamente contra a indústria pornográfica, dada a objetificação do corpo feminino. Em sentido contrário, o feminismo pró-sexo e pós-pornô se apropria dos meios de produção desta mesma indústria misógina, juntamente com outras minorias sexuais, para elaborar novos imaginários anti-patriarcais, como afirma Paul Beatriz Preciado (2019, s/p).

No Cabaré Político Multimídia que Nadia idealiza, vídeos, intervenções urbanas, músicas e textos se intercalam, numa rede de conexões que projeta a figura de La Fulminante, cuja sexualidade emancipatória confronta a misoginia naturalizada socialmente, fazendo da artista um exemplo significativo da tra(d)ição do cabaré sudaca no que diz respeito à emancipação feminina.

\section{7aㅡ Tra(d)ição: refúgio na cisheteronormativolândia}

O mesmo processo colonial que desencadeia o patriarcado de alto impacto na Abya Yala, mais violento que o próprio modelo patriarcal praticado pelo branco europeu, atinge por extensão corpos feminilizados, sexo-gênero dissidentes, além da figura específica das

${ }^{10}$ Maiores informações estão disponíveis em: <https://www.congresodelospueblos.org/\#>. Acesso em: 02 abr. 2021. 
mulheres. Isso porque, como já dito neste texto, o binarismo homem/mulher imposto pela colonização nunca correspondeu à realidade de diversos povos originários, pois:

Como é sabido, povos indígenas, como os Warao da Venezuela, Cuna do Panamá, Guayaquís do Paraguai, Trio do Suriname, Javaés do Brasil e o mundo inca pré-colombiano, entre outros, assim como vários povos nativos norte-americanos e das nações originárias canadenses, além de todos os grupos religiosos afro-americanos, incluem linguagens e contemplam práticas transgenéricas estabilizadas, casamentos entre pessoas que o Ocidente entende como do mesmo sexo e outras transitividades de gênero bloqueadas pelo sistema de gênero absolutamente engessado da colonial / modernidade (Segato, 2012, p.116).

Uma extensa pluralidade de gêneros e sexualidades foi criminalizada pelas jurisdições dos Estados-Nações Etno-Burgueses, o que se desdobrou em uma LGBTQIfobia mais violenta nas ex-colônias, a exemplo do que aconteceu com a misoginia. Este nível de repressão parece traduzir a ambiguidade entre desejo e ódio que fizeram do Brasil notório como país que mais mata pessoas trans no mundo - que aqui chegam a ter uma expectativa de vida de 35 anos, o que é menos da metade da média nacional (Benevides; Nogueira, 2021) - e, ao mesmo tempo, o país que mais consome pornografia trans na internet (Benevides, 2020).

Consagrada nos cabarés do bairro da Lapa, na cidade do Rio de Janeiro da década de 1920, a figura de Madame Satã parece congregar as contradições que configuram a sétima tra(d)ição do cabaré sudaca: a condição cuir. Nordestino, homossexual, negro, pobre e marginalizado, filho de lansã e Ogum¹1 e devoto de Josephine Baker'2, João Francisco dos Santos deixa sua marca definitiva no imaginário da cidade ao elaborar a persona de Madame Satã, que fundia a virilidade presente na figura do malandro com a delicadeza e feminilidade dos números de transformismo que apresentava (Streva, 2019).

O conjunto das subalternidades sociais (negritude, migração, pobreza, origem nordestina, etc.) conjugado à condição de homossexual, configura, em Madame

${ }^{11}$ lansã e Ogum são dois Orixás em cosmogonias de matriz africana, a exemplo da nigeriana. A primeira, de arquétipo feminino e guerreiro, é associada aos ventos, aos raios e tormentas. O segundo, de arquétipo masculino e também guerreiro, é associado ao ferro, às guerras e à tecnologia.

${ }^{12}$ Cantora e dançarina negra estadunidense, naturalizada francesa, cujas performances sensuais da década de 1920 abriram espaço para uma atuação mais política na década de 1950, no que diz respeito ao combate ao racismo por meio do Movimento Pelos Direitos Civis. 
Satã, uma sexo-dissidência anti-hegemônica. Sua figura não replica, por exemplo, o modelo gay sintonizado com a lógica do Pink Money, segundo à qual a branquitude homossexual se sintoniza com os valores capitalistas. Ao contrário, marginalizada mesmo entre os marginalizados, Satã se aproxima da ideia de queer, termo que em sua acepção anglófona se popularizou como modo de desqualificação de pessoas sexo-gênero dissidentes, não-brancas, estrangeiras, pobres, entre outros marcadores sociais - conferindo à sua aplicação dimensões racistas, classistas, xenófobas, para além das LGBTfóbicas.

Segundo Sayak Valencia (2015) o termo é contra-apropriado pelas mesmas minorias vitimizadas pelo seu uso, no sentido de uma afirmação e fortalecimento de suas diferenças perante o avanço das políticas neoliberais dos Estados Unidos da América (EUA) da década de 1980. A filósofa mexicana prefere grafar o termo com a letra C, cuir, marcando geopoliticamente seu lugar de fala, bem como a impossibilidade de um copy-rigth preciso, já que a palavra queer não provém do inglês, possuindo bases anteriores. Tendo sido empregada desde o século XVI como quer- no sentido de perverso, estranho, torcido em contexto germânico, derivado do baixo-alemão -, desdobrando-se possivelmente da palavra twerh com sentido de oblíquo no alto-alemão antigo - que, por sua vez, provavelmente se desdobra de terkw - cujo sentido é torcer, girar, na língua proto-indo-europeia -, o termo queer/cuir se refere etimologicamente àquilo que desvia, distorce.

Distorcendo e desviando, Madame Satã encantou e assombrou o imaginário da sociedade carioca com suas memoráveis performances, que mesclavam musicalidades e teatralidades populares marginalizadas na época, como o samba e a capoeira, além das referências ao imaginário do candomblé. Décadas depois, em plena ditadura militar brasileira, o grupo Dzi Croquettes desvia, distorce os paradigmas do cabaré com sua espetacularidade cuir, plena de sensualidade andrógina.

Dos tempos em que estudei em Salvador, cursando doutorado na Universidade Federal da Bahia, recordo-me com especial carinho do Âncora do Marujo, conhecido cabaré que mantém a tra(d)ição das espetacularidades transformistas e travestis no centro da cidade. Em seu pequeno espaço, frequentemente preenchido por um público muito participativo, o Âncora se 
manteve ao longo dos anos como um exemplo de (re)existência de teatralidades nada hegemônicas, desviantes, cuir, numa fronteira tênue entre arte, religiosidade e dissidência - como pode ser visto no filme de Victor Nascimento intitulado Âncora do Marujo, de $2016^{13}$.

Diferente de outras casas noturnas voltadas a clientes LGBTQIs e localizadas em bairros mais nobres, cuja frequência de turistas brancos é notável, o Âncora, como autêntico cabaré, rompeu sempre com a fronteira entre público e performer, configurando-se em espaço de socialização intensa, de (re)encontros, um refúgio na cisheteronormativolândia, termo que cunhei para qualificar:

Não apenas a construção e a ocupação imagética do espaço urbano desde uma naturalização fantasiosa que generaliza o modelo cisheteronormado, mas a celebração reiterada desta ficção - já que não correspondente à pluralidade de práticas e identidades que dela dissidem. Tal celebração se dá na reafirmação da família nuclear (pai, mãe e filhos - estando os dois últimos sob o domínio do primeiro) como representação social majoritária, a exemplo dos anúncios publicitários que servem de espelho para a manutenção do ideal de si, numa tonificação da autoimagem narcisista do patriarcado e ratificação do seu direito ao espaço público (Braga, 2019, p.153-154).

Neste sentido, a cisheteronormativolândia configura um modo de espetacularidade específica adotada como norma social. De forma alternativa, assim como o Âncora do Marujo em Salvador, a Casa Club Roshell, na cidade do México, configura-se como um refúgio e, ao mesmo tempo, maquinaria contra colonial ao valer-se da espetacularidade do cabaré para fortalecer redes de afeto e subjetividades gênero-sexodissidentes.

Em entrevista a mim concedida no ano de 2018 (Braga, 2019), Roshell Terranova, proprietária e artista da casa que conheci depois de assistir ao filme Casa Roshell, da chilena Camila José Donoso ${ }^{14}$, contou-me ser a casa um misto de escola de travestismo, organização pela defesa de pessoas LGBTQI+ e cabaré. Assim, além de poderem comprar pacotes com direito a aulas e roupas para extrapolarem os papeis de gênero a que estão submetidos na

\footnotetext{
${ }^{13}$ O trailer do filme pode ser visto em: < https://vimeo.com/142171644>. Último acesso em 20 abr. 2021.

${ }^{14} \mathrm{O}$ trailer do filme pode ser visto em: < https://www.youtube.com/watch?v=1youlBef2Zc $>$. Último acesso em
} 20 abr. 2021. 
cisheteronormativolândia, seus clientes e amigos também podem buscar pela defesa de sus direitos, bem como aprimorar seus dotes artísticos por meio do cabaré noturno, aberto ao público, que desvela o rico imaginário do cancioneiro mexicano, das vedetes, das estrelas de cinema e etc.

Se o cabaré foi sempre um refúgio para corpos dissidentes, na Abya Yala ele parece poder configurar também uma espécie de tecnologia cuir anti-patriarcal.

\title{
Inconclusões, pocessualidades
}

Ao longo deste texto, busquei retomar singularidades da arte do cabaré que o tornaram, historicamente, uma espetacularidade anti-hegemônica. Dando ênfase ao seu desenvolvimento no contexto sudaca, busquei ressaltar o quanto sua capacidade de questionar o cânone teatral se acentuou, em parte mantendo seu legado subversivo, em parte voltando-se contra o próprio contexto colonial que o efetivou naquilo que se convencionou chamar de América Latina.

Eis aí sua tra(di)ção: manter-se fiel à subversão. Afinal, como nos fala Nilton Bonder (1998, p.19):

\begin{abstract}
É preciso errar, infringir, violar e transgredir o status quo para que possa haver uma transcendência desejada pela própria tradição traída. Da mesma forma que a tradição precisa de traição, que a preservação precisa da evolução, que o acerto de hoje depende do erro de ontem, o contrário também é verdadeiro. Porque a evolução só é possível quando existe uma manifestação para ser constatada, aviltada.
\end{abstract}

A tra(d)ição como ética do cabaré decolonial e sudaca opera multidirecionalmente. Contudo, trair, neste contexto, nada tem a ver com práticas de apagamento que caracterizam subjetividades atravessadas pela lógica do capital. Esta competitividade exacerbada que se replica também em ambientes artísticos, nos mercados de arte, desdobrando-se em espoliações, silenciamentos, auto-publicidades tacanhas e outras canalhices, não faz mais do que seguir as regras do sistema-mundo. Nada arranham, nada podem ter de revolucionário ou subversivo, ainda que assim se narrem.

E quantas vezes, por baixo de discursos desconstruídos, não vemos se 
reencenarem práticas de vampirismo colonial? Sob a narrativa de "grupo" ou "coletivo", quanto individualismo pode se camuflar? Mas atenção, isso é lealdade canina a um sistema global baseado na subserviência e na exploração. Tra(d)ição é outra coisa.

A tra(d)ição do cabaré, por exemplo, implica numa revisão da própria história, incluídos aí os privilégios. Implica na impossibilidade de pureza, de lealdade a qualquer modelo imposto. Improviso sem fim, pura processualidade, nenhuma conclusão. Nas palavras de Rafael Guimarães (2020, s/p), uma moquecagem, já que a moqueca:

No encontro com o outro, pode conectar-se com a perspectiva de grupelhos de Félix Guattari, já que ele propõe que poderíamos ser muitos grupelhos, diferentes entre si, aliando-se frente ao poder hegemônico. Sindicatos, coletivos, grupos, comunidades, agremiações muitas. Aldeias, terreiros, quilombos, vales, redes. Muitas e muitas moquecas, algumas contemplariam algumas pautas, outras se dedicariam a outras. Nem mais, nem menos. Só muitas moquecas, compartilhadas, frente ao poder colonial vigente. Porque moqueca é, em si, anti-hegemônica. É ruído, gaguejo, mistura, cruzo. Gozo, pulsão de vida, potência, devir. Não precisa de corporativismo nem se presta a isso. É singularização, porque muda, porque está em movimento dinâmico.

Heterodoxos grupelhos em rede, compostos por subjetividades insubordinadas, teceram ao longo dos séculos esta espetacularidade dissidente cujo potencial de insurgência se intensifica na Abya Yala. As sete tra(d)ições aqui descritas não pretendem dar conta da multiplicidade de desvios possíveis no âmbito do cabaré, mas sensibilizar a percepção para sua existência. A relação com os sete pecados capitais, presentes no imaginário cristão, também não é ocasional. Ela remete a impossibilidade de apagamento de uma história marcada pela violência do projeto colonial - sendo o cristianismo a religião oficial desde empreendimento -, desviando e distorcendo a moralidade imposta no sentido do fortalecimento do que dela diverge.

“Herança... Maldita... Gostosa”, balbuciava uma das atuantes em resposta à percepção de Oswald de Andrade (2007, s/p) sobre a "contribuição milionária de todos os erros", numa das cenas de Cabaret Glicose: um cabaret decolonialista!, já citado anteriormente. Afinal, como nos lembra Gloria Anzadúa (2015, p.142): “Es 
difícil distinguir entre lo heredado, lo adquirido y lo impuesto". E, neste contexto, como bem posto por Silviano Santiago (2000), impossibilitado de voltar às origens apagadas pela colonialidade, impossibilitado também de ser reconhecido nos espaços da hegemonia euro-centrada, que outro melhor papel para o intelectual latino-americano senão o daquele que eclipsa o cânone desde sua condição impura e fronteiriça?

Desobediência a qualquer modelo imposto, ainda que seja o próprio. Quebrado o espelho, a cara ferida de Narciso estampa uma indisfarçável cicatriz. Estranha flor de beleza singular, refletida em distintos cacos: multiplamente, em cada ruptura, o amor à própria diferença.

\section{Referências}

ANDRADE, Oswald de. Manifesto da poesia pau-brasil . Porto Alegre: UFRGS, 2007. Disponivel em: https://www.ufrgs.br/cdrom/oandrade/oandrade.pdf. Acesso em: 06 mai. 2021.

ANZALDÚA, Gloria. Borderlands/La frontera: la nueva mestiza. Trad. Elia Cantú. Metepec. Cidade do México: Programa Universitario de Estudios de Género de La Universidad Autónoma de México, 2015.

ARISTÓTELES. Arte Poética. São Paulo: Martin Claret, 2007.

BENEVIDES, Bruna. Brasil lidera consumo de pornografia trans no mundo ( e de assassinatos). Revista Hibrida. Abr. 2020. Disponível em: https://revistahibrida.com.br/2020/05/11/o-paradoxo-do-brasil-no-consumo-depornografia-e-assassinatos-trans/. Acesso em: 05 abr. 2021.

BENEVIDES, Bruna G.; NOGUEIRA, Sayonara Naider Bonfim (ORG.). Dossiê dos assassinatos e da violência contra travestis e transexuais brasileiras em 2020. São Paulo: Expressão Popular, ANTRA, IBTE, 2021. Disponível em: https://antrabrasil.files.wordpress.com/2021/01/dossie-trans-2021-29jan2021.pdf . Acesso em: 05 abr. 2021.

BERTHOLD, Margot. História Mundial do Teatro. Trad. Maria Paula V. Zurawski. São. Paulo: Perspectiva, 2000.

BETHÂNIA, Maria. Drama 3o Ato: Luz Da Noite. Rio de Janeiro: Philips, 1973, disco de vinil.

BETHÂNIA, Maria. A cena muda. Rio de Janeiro: Philips, 1974, disco de vinil. 
BIÃO, Armindo Jorge de Carvalho. Etnocenologia e a cena baiana: textos reunidos. Salvador: P\&A Gráfica e Editora, 2009.

BRAGA, Cleber (Cleber Rodrigo Braga de Oliveira). Fantasmografias: sexílio, arte e ativismos cuirdecoloniais na transfronteira mexicobrasileira. Tese (Doutorado em Cultura e Sociedade) - Instituto de Humanidades, Artes e Ciências, Universidade Federal da Bahia, Salvador, 2019. Disponível em: https://repositorio.ufba.br/ri/handle/ri/32022?fbclid=IwAR2YVe-X-

f4_2DPGC_J5BPsDC7URkp-UNK05y85wBXPNHx99bTgqqnzEtJk. Acesso em: 10 mai. 2020.

BRECHT, Bertolt; WEILL, Kurt. Surabaya Johnny. Versão: NEVES, Duda; VERGUEIRO; Sílvia. In: MOREIRA, Cida. Abolerado Blues. São Paulo: Lira Paulistana, 1983, disco de vinil.

BRECHT, Bertolt. Teatro dialético. Seleção e tradução de Luiz Carlos Maciel. Rio de Janeiro: Civilização Brasileira, 1967.

BONDER, Nilton. A alma imoral: tradição e traição através dos tempos. Rocco: Rio de Janeiro, 1998.

COHEN, Renato. A performance como linguagem. São Paulo: Perspectiva, 2009.CORREAA, Amélia Siegel; OLIVEIRA, Luana Hauptman Cardoso de. A arte relacional e a participação do público: aproximações poéticas do período de 196070 com a 27ạ bienal de São Paulo. Mediações, Londrina, v. 21, n. 2, p. 254-278, jul.dez. 2016.

CRUCIANI, Fabrizio.; FALLETTI, Clelia. Teatro de rua. Trad.: Roberta Baarni. São Paulo: Hucitec, 1999.

CHRISTINA, Streva. The carioca cabaret and dissident expressions: Tropical Montmartre' to the present day. Karpa Journal: California State University - LA, s/p, 2019. Disponível em: http://www.calstatela.edu/al/karpa/carioca-cabaretchristina-streva. Acesso em: 10 mai. 2021.

DEBORD, Guy. A Sociedade do espetáculo. Trad.: Francisco Alves e Afonso Monteiro. Lisboa: Afrofite, 1972.

FÉRAL, Josette. Acerca de la teatralidad. Buenos Aires: Nueva Generación, 2003.

FÉRAL, Josette. Por uma poética da performatividade: o teatro performativo. Trad. Ligia Borges. Sala Preta, São Paulo, v.8, n.1, 2008.

FOUCAULT, Michel. Theatrum philosophicum. Tradução: Jorge Lima Barreto. Porto; Rés, 1995.

GUIMARÃES, Rafael. Moquecar (n)a Pandemia. Disponível em: https://www.n1edicoes.org/textos/105. São Paulo: N-1, 2020. Acesso em: 05 mai. 2021. 
GUITA, Luís. Coletivo curitibano causa frenesi em Portugal. Gazeta do Povo, Curitiba: 31 de janeiro de 2015. Caderno G. Disponível em : http://www.gazetadopovo.com.br/caderno-g/coletivo-curitibano-causa-frenesiem-portugal-ejea573dn7rg8dymlvkv3jya6. Acesso em: 10 de jun. 2017.

GOLDBERG, Rose Lee. A arte da performance: do futurismo ao presente. Tradução de Jefferson Luiz Camargo. São Paulo: Martins Fontes, 2006.

ITAÚ CULTURAL. Cabaré da Rrrraça. Disponível em: https://enciclopedia.itaucultural.org.br/evento601292/cabare-da-rrrrraca. Acesso em 05 de abril de 2021.

LAGO, Mara Coelho de Souza et al. Gênero, gerações e espaço doméstico: trabalho, casa e família. Paidéia, Ribeirão Preto, v. 19, n. 44, p. 357-366, 2009. Disponivel em: http://www.scielo.br/scielo.php?script=sci_arttext\&pid=S0103863X2009000300010\&lng=en\&nrm=iso. Acesso em: 21 abr. 2021.

LANE, Rebeca. Mala Hierba. In: Obsidiana. FlowFish Records. 2018, CD.

LOBATO, Lúcia Fernandes. A Cultura Lúdica como proposta para a desconstrução do "Mito Homem Sério". Salvador: PPGAC-UFBA; Professora Associada. VI Reunião Científica da Abrace. Porto Alegre, 2011.

MIGNOLO, Walter. Hacer, pensar y vivir da decolonialidad: textos reunidos y presentados por comunidad psicoanálisis/pensamiento decolonial. Ciudad de México: Editorial Borde Sur: Ediciones Navarra, 2016.

MALDONADO-TORRES, Nelson. Transdisciplinaridade e decolonialidade. Soc. estado, Brasília, v. 31, n. 1, p. 75-97, abr., 2016. Disponível em: http://www.scielo.br/scielo.php?script=sci_arttext\&pid=\$010269922016000100075 \&lng=en\&nrm=iso . Acesso em: 19 mar. 2021.

Mogrovejo, Norma. Del Sexílio al Matrimonio. Ciudadanía Sexual en la era del consumo Liberal. Migración y Sexílio Político. Madres lesbianas, familias resignificadas. Poco sexo, más clase y mucha raza. Centro de Documentación y Archivo Histórico Lésbico de México, América Latina y Caribe 'Narncy Cárdenas'; Escuela para la Libertad de las Mujeres 'Siembra Autonomía, Cosecha Libertad'; Coletivo Editorial Pez en el Árbol, Ciudad de México: 2017.

ONU. Dia da Visibilidade Trans: 175 pessoas foram mortas no Brasil em 2020 em razão da transfobia. Disponível em: https://brasil.un.org/pt-br/109791-dia-davisibilidade-trans-175-pessoas-foram-mortas-no-brasil-em-2020-em-razao-datransfobia. Acesso em: 05 abr. 2021.

PALERMO, Zulma. El arte latinoamericano en la encrucijada decolonial. In: PALERMO, Zulma (ORG). Arte y estética en la encrucijada descolonial. Buenos Aires: Del Signo, 2009. 
PORTO-GONÇALVES, Carlos Walter. Entre América e Abya Yala - tensões de territorialidades. Desenvolvimento e Meio Ambiente. Curitiba, n. 20, p. 25-30, jul./dez. 2009.

PRECIADO, Paul Beatriz. Entrevista con Paul B. Preciado: Posporno/ Excitación disidente. Parole de Queer. Disponível em: http://paroledequeer.blogspot.com/2014/01/entrevista-con-beatriz-preciado.html. Acesso em: 15 fev. 2019.

QUIJANO, Aníbal. Colonialidade do poder, eurocentrismo e América Latina. In: LANDER, Edgardo (Org.). A colonialidade do saber: eurocentrismo e ciências sociais. Perspectivas latino-americanas. Buenos Aires: CLACSO,2005, p. 107-130.

ROUBINE, Jean-Jacques. A linguagem da encenação teatral. Rio de Janeiro: Zahar, 1982.

RUFINO, Luiz. Pedagogia das encruzilhadas. Rio de Janeiro: Mórula Editora, 2019.

RYNGAERT, Jean Pierre. Ler o teatro contemporâneo. São Paulo: Martins Fontes, 1998.

SAIDEL, Giorgia Barbosa Conceição. A burla do corpo: estratégicas e políticas de criação. 2011. Dissertação (Mestrado em Artes Cênicas) - Universidade Federal da Bahia, Salvador, 2011. Disponível em: https://repositorio.ufba.br/ri/handle/ri/27102. Acesso: 10 abr. 2021.

SANTIAGO, Silviano. Uma literatura nos trópicos: ensaios sobre a dependência cultural. RJ: Rocco, 2000.

SCHUCMAN, Lia Vainer. Sim, nós somos racistas: estudo psicossocial da branquitude paulistana. Psicologia \& Sociedade, v. 26, n. 1, p. 83-94, 2014.

SEGATO, Rita Laura . Gênero e colonialidade: em busca de chaves de leitura e de um vocabulário estratégico descolonial. E-cadernos ces [Online], n.18 , p.106-131, 2012. Disponível em : http://eces.revues.org/1533 . Acesso em 15 abr. 2021.

SPIVAK, Gayatry Chakravorty. Pode o subalterno falar? Belo Horizonte: UFMG, 2010.

SUDARE, Lívia. DIE HÖCHSTE EISENBAHN: um aviso do cabaré alemão diante da ameaça nazista. Sala Preta, 19(2), São Paulo, p. 48-63, 2019. Disponível em: https://doi.org/10.11606/issn.2238-3867.v19i2p48-63. Acesso em 17 de fev. 2021.

SZONDI, Peter. Teoria do drama moderno. São Paulo: Cosac Naify, 2001.

WISNIK, José Miguel. Letra de música é poesia? Entrevista realizada em 10 out. 2019. SESC TV. Disponível em: https://www.youtube.com/watch?v=WOLJWGe37i4. Acesso em: 06 de abr. 2021. 
VALENCIA, Sayak. Del Queer al Cuir: ostranénie geopolítica y epistémica desde el sur glocal. IN: LANUZA, Fernando R. ; CARRASCO, Raúl M. (ORG). Queer \& Cuir: políticas de lo irreal. Cidade do México: Fontamara, 2015.

VENEZIANO, Neyde. O Teatro de Revista no Brasil: dramaturgia e convenções. SesiSP: São Paulo, 2013.

Recebido em: 23/05/2021

Aprovado em: 12/08/2021 